\title{
Solitude as an Act of Hedonism in Bryce Andrews' Badluck Way
}

\author{
Mohd Zaimin bin Haris Fathillah ${ }^{a}$ \\ zaiminharis@gmail.com \\ Universiti Kebangsaan Malaysia \\ Ravichandran Vengadasamy ${ }^{b}$ \\ ravicv@ukm.edu.my \\ Universiti Kebangsaan Malaysia
}

\begin{abstract}
This paper argues that the author's preference for solitude in Bryce Andrew's Badluck Way is essentially hedonistic in nature. Solitude constitutes human existence and experience. The concept of 'pain and pleasure' predicates hedonism. The intersectionality between experiential solitude and hedonism is unfortunately inconceivable despite a plethora of discourse including literature. In numerous literary texts, solitude has been the pivotal entry point to ascertain and expound both fictional and nonfictional characters' actions and behaviours. The same can be said about hedonism. However, there is little to no literary studies conducted to explore the common linkage between solitude and hedonistic views. Fred Feldman's (2004) Attitudinal Hedonism theory and his six Intrinsic Attitudinal Pleasure features underpinned the study. Findings disclosed that many pleasure taking aspects in solitude are inherently hedonistic. Selected excerpts revealed that hedonism and pleasure taking played a predominant role in asserting the author's predilection for solitariness. This paper responds to the need for investigation of the singularisation of solitude-hedonism concept as a means of heightening interdisciplinary awareness and enabling inter-discourse studies of literary and philosophical scholarship alike.
\end{abstract}

Keywords: Solitude; Pleasure; Hedonism; Intrinsic Attitudinal Hedonism; Ranch Literature

\section{INTRODUCTION}

This paper focuses on Ranch Literature, a sub-genre encompassing literatures that deal with ranching in the American West. Pritchett (2004) notes that the genre fundamentally concerns literature that has a ranch as its primary setting, or which takes ranch life as a primary theme, as well as literature categorised as nature writing that concerns ranching or ranch life. Pritchett (2004) highlights the emergent themes: connection to particular places; connection to the community living in such places; and connection to the existing culture within that place and community from this genre.

Ranch Literature branches off from nature writing that has emerged as the most "lively field of American Literature" (Lyon, 2001, p. 131) as evidenced by the sudden primary texts increase and serious scholarly attention drawn to the genre (Pritchett, 2004) especially during the second half of the twentieth century. Since the 1960s, nature writing has broadened its focus to include rural and agricultural environments (Scheese, 1996). Pritchett (2004) explains nature writers explore "the ethical commitments to stewardship and examination of land use issues" (p. 7). The American nature writing discourse has grown with immense contribution from writers with an agricultural stance (Lyon, 2001).

\footnotetext{
${ }^{a}$ Main author

${ }^{b}$ Corresponding author
} 
Bryce Andrews impeccably fits the bill as a nature writer with an agrarian viewpoint whose book discusses the subject of ecology presented through the intricate and reciprocal relationship humans share with wild animals and ranch lands. His memoir titled Badluck Way: A Year on the Ragged Edge of the West is a taut depiction of ranch life, and a thoughtful view of the agribusiness. Bryce Andrews is a Montana-based author, rancher and conservationist, a three-pronged life that was shaped by his transformative experience ranching on the Sun Ranch, the setting of his first book (Lambert, 2015). Ranching has long been a staple of Montana's culture and economy ("Ranching in Montana", n.d.). The most part of Montana is a sprawling rangeland used in the livestock-ranching industry for the beef cattle and sheep production, and with the slightest trace of human habitation (Crowley, 2020). Geographical remoteness and sparse population trivialise human interaction but embellish unparalleled solitude.

The first Spanish explorers firmly established ranching in the New World of Americas when they brought cattle and cattle-raising knowhow with them ("Ranching", n.d.) In the western United States, ranching is derived from vaquero culture. Mexican vaqueros, or cowboys were hired by the European-American pioneers to work on ranches, and vaquero traditions of horsemanship, equipment, and language significantly influenced other working cowboys (Marshall, n.d.). These cowboys exemplify the voluntary nature of solitude as "they would rather spend time making wages on horseback or in a line camp removed from town and regular society" (Marshall, n.d., para,2).

Solitude is principal in this paper. It is human nature to pursue intermittent withdrawal from the world. Koch (1994) defines solitude as a time of experiential disengagement from other individuals. To encapsulate his solitude definition, Koch considers other features of solitude (e.g. the physical isolation, the freedom, the silence, etc.), and pinpoints the absence of companion in one's world as the core essence. Coplan and Bowker (2014) note that humans instinctively react to solitude in diverse ways for many reasons.

Historically, this intensifying need for self-communion shares its roots with an early Christian tradition which runs back to the early Christian desert fathers. Individuals who seek temporary or permanent solitude in remote and isolated sites are called hermits or eremites. Some of the early Christians in fourth-century Egypt initiated a monastic move as they sought living an ascetic yet precarious existence in isolation in order to attain holiness (Haines-Eitzen, 2018). In the two opening lines of Life of Paul of Thebes, St. Jerome wrote "It has been a subject of wide-spread and frequent discussion what monk was the first to give a signal example of the hermit life." Paul of Thebes and Anthony of Egypt were said to have initiated the movement. Athanasius's Life of Anthony and St. Jerome's Life of Paul of Thebes are two early known biographies discussing Christian monasticism, but Jerome' work was heavily influenced by Athanasius' (Jotischky, 2011). Athanasius was the first author to explicitly write about Christian monasticism. The translation of his work into Latin later showed how influential it had become (Jotischky, 2011). In addition to this, Haines-Eitzen (2018) notes how Anthony's departure in search of solitude and contemplation became a prime example for later Christians for emulation of monasticism.

The advent of Romanticism signalled another momentous shift concerning solitude. Preceding the era, the stigma of isolation was ever-present. Atomistic individuals were seen as deviating from the true human nature (Eagleton, 2020). British professor David Vincent states that in the late $18^{\text {th }}$ century, solitude was deemed unprecedented and innately damaging experience (Macdonald, 2020). He also asserts that the advertent disconnectedness from sociability for mere self-enjoyment was always met with suspicion or pity, which gave rise to an ambivalent status that stigmatised solitude (Macdonald, 2020). The arrival of romanticism eradicated this stigma. Berlin (1999) notes how Romanticism brought about the significant shift in the Western lives and thought. Vincent (2020) spotlights solitude as a response to the 
threats of increasingly crowded populations stretching back to the Romantic Movement. Celebrating solitude was seen as a new attitude towards nature that sprang up among English poets (Berlin, 1999). This fresh movement was abetted by the modernity of international transport systems which enabled unmediated relationships between men and nature from the mid-nineteenth onwards (Vincent, 2020). This is also ostensible in the treatment of solitude as the exceptional Romantic subject explored in oeuvres by Coleridge, Byron, Poe (Bolea, 2017).

Hedonism probes what constitutes the good life. Humanity, to use a Freudian jargon, are psychoanalytically inclined to seek pleasure (Hijab, 2018). Succinctly, hedonism views one's life is better if one's pleasure exceeds one's pain (Feldman, 2004). In hedonistic discourse, many formulated theories explicate the life based simply on the idea of "pleasure over pain'. Feldman (2004) states that the cardinal intuition of hedonism, despite its many forms (e.g. Sensory/Default Hedonism, Psychological Hedonism, Ethical Hedonism, etc.), is that the pleasant life is the good life. Therefore, it is relevant to provide critical accounts of some historically important forms of hedonism. Jeremy Bentham (1789), one of the figureheads and defenders of Hedonism, brandishes 'pleasure' and 'pain' as the life's two Lords in his book An Introduction to the Principles of Morals and Legislation. Bentham (17481832) argued for several forms of hedonism, which are now referred to as Prudential Hedonism, Hedonistic Utilitarianism, and Motivational Hedonism (Moore, 2019). His contention was happiness was the ultimate good and happiness was the maximisation of pleasure and the minimisation of pain that governed moral behaviour (Weijers, n.d.). It was Bentham who preached utilitarianism, 'the greatest good for the greatest number' (Hijab, 2018) that was evident in Bentham's greatest happiness propriety that states actions are considered morally right if they seem to maximise the happiness of all the people (Weijers, n.d.).

Bentham's protégé, John Stuart Mill (1806-1873), who was exposed to utilitarianism, and whose theories had similar traits with the mentor's but were dichotomous on the nature of pleasure (Feldman, 2004), was among the influential hedonists. He subscribed himself to the hedonistic varieties that are now known as Prudential Hedonism, Hedonistic Utilitarianism, and Motivational Hedonism (Weijers, n.d.). Mill's version of hedonism was made famous in his book Utilitarianism as he exclaimed that pleasure and absence of pain as desirable as the premise of human goals (Hijab, 2018). Feldman (2004) points out Mill's allusion to a distinction between 'higher pleasures' - pleasures of the intellect and 'lower pleasures' - bodily pleasures. His book On Liberty made his hedonistic standpoint clear through the 'harm principle' that states one has the liberty to do whatever they wanted as long as no harm is inflicted on anyone else (Hijab, 2018). It is also important to note that discussion on hedonism had commenced hundreds of years before Bentham and Mill and continues to this date. A Hedonistic Egoist, Aritippus (c.435-356 B.C.E.) founded the Cyrenaic school of hedonism and chanted physical, bodily pleasures over mental, intellectual pleasures (Feldman, 2004). Epicurus (c. 341-271 B.C.E.) founded Epicureanism and preached about Normative Hedonism that advocates the avoidance of extolling the wonders of sensory pleasures (Feldman, 2004) since these are unnecessary pain-inflicting pleasures that lead to desiring for more and better of the same pleasures (Weijers, n.d.).

Solitude and hedonism outline this paper. Undoubtedly the two concepts have been under analytical lens of literary scholarship, but they have not yet been researched as a converged motif. Persistent library research has thus far yielded in the negative. This gap in research necessitates the current epistemic endeavour. In addition, the ranch memoir used in this analysis is relatively new, and no research has been proposed to dissect the corpus literarily in relation to solitude and hedonism. Therefore, this paper intends to link the author's solitude with hedonism, and thus extend the existing body of knowledge concerning solitude and hedonism in Ranch Literature. 


\section{REVIEW OF PAST STUDIES}

Solitude is pervasive in numerous oeuvres. Milner (2018) examined Walter de la Mare's writings for solitude and connectedness. He argued solitude and connectedness form each end of an axis of concern in de la Mare's work which can be explored for degrees of solitude and connection that exist between the two opposing states. Walter de la Mare's solitude is a matter of mind and spirit, and only exists in varying degrees as absolute solitude is elusive. Another key feature of the poet's solitude is it is both "feared and desired" (Milner, 2018, p. 53). Connectedness in de la Mare's work is a matter of mind and spirit, and depicted as the degree of communication that is possible, and like solitude, absolute connectedness is impossible. The notion of "solitude is the complete absence of connectedness, and connectedness is the extinction of solitude" is interspersed throughout de la Mare's work (Milner, 2018, p. 53).

Female response to solitude has been widely researched. In a study focusing only on solitude, Frank (2015) explored $19^{\text {th }}$ century novels for the role solitude played in overcoming tensions and infighting. A strong distinction set her project apart from other scholars as she clearly stated that her research privileged one form of solitude and probed what mundane aloneness meant for women. Where women were concerned in the context of the $19^{\text {th }}$ century fiction, this nuance of solitude was unveiled as the imposition of varying degrees of alienation. Her readings of the selected textuality also revealed "unevenness in women's access to intended time apart" (Frank, 2015, p. 168). Ironically the negativity associated with solitude led the women of the past literature to frame it as neither self-indulgence nor personal will, but rather solitude as a duality in the sense that was jointly constructed by personal experience and surrounding people, and this fact did not rule out its "strengthening worth" (Frank, 2015, p. 169).

On a related note, Schlau (2016) studied solitude in Discalced Carmelite nun-poetry as a means of spiritual perfection. Her readings of the poems consistently found the benefits of solitude in terms of spiritual perfection, especially mystical union with the divinity. The study also revealed that the poetry verses were expressive of "the trials and contradictions" of the ascetic road to union with the divinity (Schlau, 2016, p. 143). The verses documented "the beauty and ultimate fulfilment" of the quest they embarked on in search of mystical union as well (Schlau, 2016, p. 143). Later it was made relatively clear that the state of solitude was created and retained to claim not only the material space but also the spiritual space. This was not a gesture towards personal autonomy but rather to poeticise the path to the ultimate merging with God. In the same vein, Bessetti-Reyes (2014) investigated women's responses to solitude in the Western wilderness in texts published between 1823 and 1939. Isabella Bird was a British writer and traveller. The readings of Bird's published letters A Lady's Life in the Rocky Mountains (1873) disclosed how staunch she was in portraying her "Christian morality and propriety" with regard to the solitary living in the patriarchal West of "the absolute lawlessness and roguishness" (Bessetti-Reyes, 2014, p. 91). It was revealed that the Western brutishness did not negatively influence her character, but instead Bird preserved her "Christian virtue and purity" accentuating her spiritual perfection (Bessetti-Reyes, 2014, p. 91). Later, the study indicated that solitude in remote places allowed her to perpetuate worship. "To be alone in the park from the afternoon till the last glory of the afterglow has faded, with no books but a Bible and prayer-book, is truly delightful" (as cited in Bessetti-Reyes, 2014, p. 99).

Hedonism is recurring in opuses highlighting sensuality especially. Holton-Johnson (2012) studied Lady Mary Wortley Montagu's writings for her representation of pleasure through her "sexual libertinism" (p.1). Montagu was an exceptionally unconventional woman, and came from a British family of intellectual and financial dominance in the eighteenth century. Her extensive role in the evolutions of erotic literature was seen in her poetry and letters that were expressive of her unconventional sexuality (Holton-Johnson, 2012). The 
writings exposed her despite her attempts to be "homosexually anonymous" (Holton-Johnson, 2012, p. 53). As a keen traveller for pleasure, Montagu went abroad seeking the bodily pleasures documented in letters she intended for a private audience and own safekeeping (Holton-Johnson, 2012). Her overseas travels not only quenched her homoerotic thirsts, but also involved her lovers in "improbable experiences through the writing of detailed, pornographic letters" (Holton-Johnson, 2012, p. 53).

On the same subject, Damiani (2016) explored hedonism as part of Faustian nineteenth century paradigm for homosexual desire in Johann Wolfing Goethe's play Faust: A Tragedy and a film The Picture of Dorian Gray based on Oscar Wilde's novel with the same title. This paradigm constituted aestheticism, hedonism, and identity. Both works epitomised the homoerotic art theory of Joachim Winkelman, which was interpreted through hedonism for the theme of same-sex desire. Both of the works' main characters were inspired and experientially liberated by Dionysian elements of Greek tragedy and theatre to express their conflicting sexual urges which later led them to embracing their homosexual identity. Along the same line, Torralbo Caballero (2015) examined the treatment of hedonism and pleasure in some poetry of the Restoration Era. Literature, during the age of Restoration, experienced a significance transformation in so far as the general topic and themes within the work were concerned. Poets became conspicuously audacious in their head-on approach of illustrating the human desires for "carnal bonding" (Torralbo Caballero, 2015, p. 90). This trend developed as discussions on taboo topics were not met with any kind of religious, ethical or moral restrictions. Instead the poetry was well received as a source of enjoyment by the curious readership of the period due to its certain freshness, novelty and openness.

As separate notions, both solitude and hedonism have drawn adequate academic attention. It is relevant to point out that both concepts, though entrenched in literary fabric, have never been examined in the same breath. This study aims to examine how the notions of solitude and hedonism may be interwoven within a particular narrative.

\section{CONCEPTUAL FRAMEWORK}

In this study, solitude is seen as the object of pleasure. The analysis adopts Fred Feldman's Intrinsic Attitudinal Hedonism theory that sees pleasure as an attitude that makes a person's life better. If the person enjoys a certain fact, he is said to take attitudinal pleasure in it (Feldman, 2002). Enjoyment is an attitude that "takes propositional entities (or states of affairs) as its objects" (Feldman, 2002, p. 607). Regurgitated in Feldman (2004), attitudinal pleasure is always object-directedness.

Intrinsic Attitudinal Hedonism theorises that people gain attitudinal pleasure or pain through episodes that bear intrinsic value (Feldman, 2004). The first principles of the theory are as follow:

i. Every episode of intrinsic attitudinal pleasure is intrinsically good; every episode of intrinsic attitudinal pain is intrinsically bad.

ii. The intrinsic value of an episode of intrinsic attitudinal pleasure is equal to the amount of pleasure contained in that episode; the intrinsic value of an episode of intrinsic attitudinal pain is equal to - (the amount of pain contained in that episode).

iii. The intrinsic value of a life is entirely determined by the intrinsic values of the episodes of intrinsic attitudinal pleasure and pain contained in the life, in such a way that one life is intrinsically better than another if and only if the net amount of intrinsic attitudinal pleasure in the one is greater than the net amount of that sort of pleasure in the other.

(Feldman, 2004, p. 66) 
Intrinsic Attitudinal Hedonism is predicated on its three tenets, namely:

i. Universal Attitudinal Hedonism (UAH)

UAH conceptualizes that every episode of intrinsic attitudinal pleasure is internally good. Further, UAH conceives that all pleasures are universally central and important; hence the name Universal AH. In other words, Feldman perceives no pleasures are worthless, defeated, or transvaluated. The similar thing can be said about pain as every attitudinal pain is intrinsically bad in this theory.

ii. Pure Attitudinal Hedonism (PAH)

PAH denotes that attitudinal pleasures and pains are fundamentally the sole linkage to the value of a life. If a life is devoid of attitudinal pleasure, it is deemed valueless and unimportant. Likewise, similar claims may be made about pains and evil. To further illustrate, for individuals who never take any intrinsic attitudinal pleasure in anything, according to IAH, it is futile to attribute intrinsic value to their lives.

iii. Mental Statism

An assumption is made that episodes of intrinsic attitudinal pleasure and pain are mental states. A life value relies on facts about the mental states of the individual who lives that life. If it is the case, there is seemingly a close correspondence between two individuals with similar mental states and their relevant sort of value. As an implication, these two individuals' lives are of equal intrinsic value for them if they are indiscernible with regard to intrinsic attitudinal pleasure and pain.

(Feldman, 2004, pp. 66-67)

For textual analysis, the adopted theory will be more penetrating with the use of Feldman's six features of intrinsic attitudinal pleasure. The six features are discussed as the following:

a. The awareness of pleasure: People can take pleasure in something even if they are not completely aware that they are pleased about it.

b. Pleasure and belief: Taking pleasure in a certain state of affairs entails the aspect of believing it to be true. This belief does not have to be at the forefront of people's consciousness.

c. The transparency of pleasure: People who are pleased in a certain state of affairs and are aware of the pleasure taking could still be mistaken about the object of their pleasure.

d. Pleasure and truth: Attitudinal pleasure is not perpetually truth bound. The safest assumption to make is that if individuals take pleasure in some state of affairs, they must at least think that it is true.

e. The plurality of pleasures: Multiple, temporally overlapping pleasures and pains could simultaneously be experienced by people.

f. The temporal orientation of pleasure: The objects of attitudinal pleasure can be in the past, present or future.

(Feldman, 2004, pp. 58-63) 


\section{METHODOLOGY}

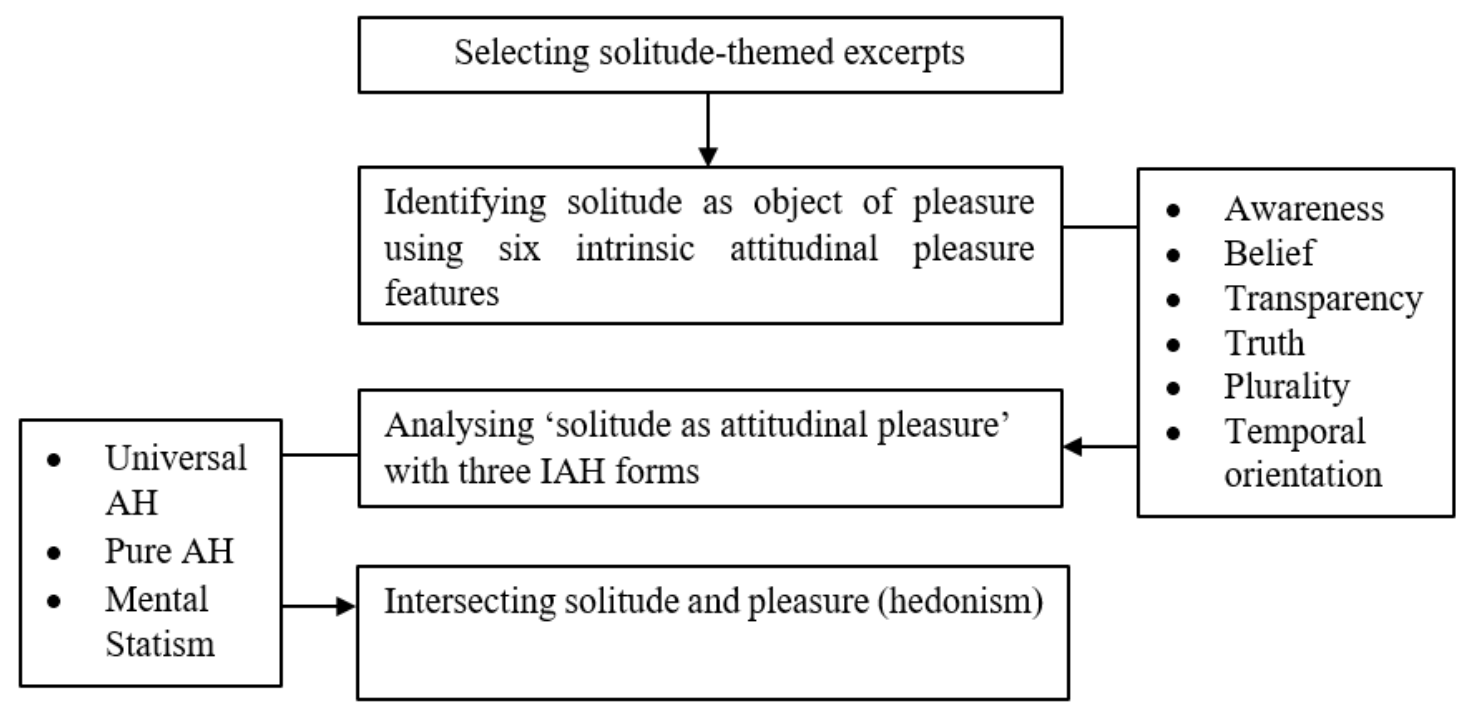

FIGURE 1. Flow chart showing progression of the study

The proposed methodology is constructed using Feldman's (2004) theory of Intrinsic Attitudinal Hedonism. As represented by the flow chart in Figure 1, the first stage of the study begins with the selection of excerpts with solitude ideas. Once selected, the solitude ideas found in the excerpts are identified as the object of pleasure by using six features of intrinsic attitudinal pleasure in the second stage. The selected excerpts need not have all six features of intrinsic attitudinal pleasure but a few. In the subsequent stage of the study, once identified as attitudinal pleasure, the solitude ideas contained within the excerpts are analysed for discussions in relation to three forms of Intrinsic Attitudinal Hedonism theory. In the final stage, the two concepts of solitude and hedonism are intersected.

\section{FINDINGS}

This study conducts a philosophical probing into the contention that the author's solitude is inherently hedonistic. Koch (1994) defines solitude as the situation of voluntary disengagement from the world. Pre-ranch life, his yearning for solitude was already palpable. Bessetti-Reyes (2014) documented 'yearning' as the chief factor of seeking solitude. 'Getting lost was easy' (p.4) was his own admission insinuating that living a solitary, carefree life was his goal. The author lent himself perfectly to one of the notions of existentialism - authenticity. It addresses an authentic moral act entailing commitment, transparency, and autonomy (Crowell, 2017). Existentially, Andrews was committed in acting the way he chose as his own whilst being transparent with regard to his situational identity and resolute to a certain course of action. He acted in accord with his nature which made him morally authentic.

Andrews's lone travel from Seattle down the coast to San Diego reverberated a young man's perpetual personal predilection for solitude as he vividly recollected:

"I took trains that rattled across the Southwest: Phoenix, Tucson, San Antonio, a hundred map dots in between. I got a hotel room in New Orleans for my twenty-third birthday, did what everyone does there, then ran north to get away. From D.C. and New York to Chicago, where clinker ice hissed against a concrete breakwater, I was quick and free. My feet had barely touched the ground since California."

(Andrews, 2014, pp. 4-5) 
Here, Andrews notably strove for solitude as his object of enjoyment. Later, he made a midnight crossing into Juarez, Mexico and hitchhiked his way around Mexico to places, such as Copper Canyon and Baja before crossing back into the United States at Tijuana. From existential perspectives, he was en route to self-making, a condition of authenticity as authentic individuals commit themselves to the role they come to adopt (Crowell, 2017). Authenticity governed the manner in which he engaged in his role as a solitudinarian. Being away in a foreign land guaranteed his solitude intactness as unfamiliarity shielded him, which is convergent with de la Mare's notion of solitude is the complete absence of connectedness (Milner, 2018). No aspects of the foreign land could make him connect with his homeland as nothing or no one could make him reminisce about home as familiarity could potentially derail his pursuit of solitude.

Contentiously, Andrews' solitude is intrinsic in nature when examined using the six intrinsic attitudinal pleasure features. First, the awareness of pleasure is indicative of one taking pleasure in something despite being utterly unaware that one is pleased about it (Feldman, 2004). Travelling across the United States and later to Mexico was part of his idea of getting lost. It appears that travelling was his object of enjoyment. To clarify, seemingly he was pleased about travelling, but in reality, he was entirely unaware that the pleasure came not from all the travelling but the experience of being alone in any place he had been to. The second feature suggests the author take pleasure in solitude that he believed it to be true. This explains his obsession with the West as he admitted later in "... ever since I can remember, I've been obsessed with the West" (Andrews, 2014, p.5). His first time on a ranch owned by Pat Zentz, his father's friend, taught the 7-year-old author how invaluable solitude was. Also, the West is synonymous with solitude and remoteness of the wilderness. Emotion has the indispensable part to play in human reconciliation with the natural world (Khosravi, Vengadasamy and Raihanah, 2016). The piece of evidence can be seen in the excerpt below:

"Every summer until I turned eighteen, I returned to the Zentz Ranch to work for nothing, or next to nothing, finding recompense in the little calluses on my palms. Whenever I went home to the damp claustrophobia of Seattle, I would dream about big, dry, lonely country."

(Andrews, 2014, p.6)

His obsession led him to constructing the belief that he took pleasure from his times on the ranch, and solitude is the logical reason why he dreamed of escaping Seattle to go back to the 'big, dry, lonely country'. This idea - claustrophobia versus loneliness - envisages the intense search for solitude, and even explains the reason why he made his dream a reality because he simply believed in it. The third feature, the transparency of pleasure, indicates that the author thought and realised he was taking pleasure in the land stewardship, but was mistaken about the object of his pleasure. This is conceivable in the excerpt below:

"I came back the next summer - stayed longer, worked a little bit harder, got paid two bucks an hour. I learned to roll up rusty, ground-bound strands of barbwire. In the summers that followed, I built fence, fixed fence, moved cows, and learned how to catch and ride a horse."

(Andrews, 2014, p. 6)

Was becoming a hand the only explanation for his loyalty of going back to the ranch every summer? Was he taking pleasure in completing all the hard work? This paper argues otherwise. Later, it was revealed that he wanted to escape 'the damp claustrophobia of Seattle', and he often dreamed about 'big, dry, lonely country' (Andrews, 2014, p. 6). His younger self thought that he found satisfaction in doing all the ranch-related tasks, but unbeknownst to him, the real object of his pleasure was the solitary living in a lonely country, and that was what he was deprived of. Pleasure and truth, the fourth feature of attitudinal pleasure, suggests that 
attitudinal pleasure is not always truth-oriented (Feldman, 2004), but if the author took pleasure in the idea of going back to the 'big, dry, lonely country', he then must at least think that it was true, which somehow explains the obsession he possessed.

The above-cited instances correspond to the next feature, the plurality of pleasures. At this juncture, the author enjoyed multiple, temporally overlapping pleasures as he was pleased to be in the 'big, dry, lonely country', doing multitude of ranch jobs removed from other humans, and when all the work was done, 'I lay faceup on the truck's roof looking into the deep blue bowl of the sky' (Andrews, 2014, p.6). This led to authenticating solitude as the plausible reason for his obsession. The last feature emphasises the objects of any attitudinal pleasure can be in the past, present, or future (Feldman, 2004). This shows that the author's solitary pleasures persisted from the first time he experienced that kind of living as indicated by his return to work as a hand ranch in much later stage of his life. When the author was seven, he had his first exposure to the type of living, and it reflected throughout his life as he made the return to the Zentz Ranch every summer until he turned eighteen. The solitary pleasures continued to exist when he decided to apply for a seasonal position on the Sun Ranch later in his life as he exclaimed, '... I could not put the idea of ranching from my mind' (Andrews, 2014, pp. 6-7). His object of pleasures and their effects started in the past and evidently manifested in future as he applied for the position.

Intrinsic Attitudinal Hedonism theorises every episode of intrinsic attitudinal pleasure is intrinsically good (Feldman, 2004). The ranch life greatly influenced the author's every decision making and thinking process. His steadfastness was categorically the outcome of the solitary pleasures he had experienced. When this is considered, every episode of intrinsic attitudinal pleasure that the author experienced from the age of seven onwards, according to Universal AH, is in itself good. These living in solitude episodes must be intrinsically good in relation to the theory as the author kept coming back for more up until he applied for the job and was successful in getting hired to work on the Sun Ranch. This goes well with the idea that solitude is a biological need as proposed by Thomas (2017). Pure AH, in the meantime, implies that pleasures and pains essentially correlate with a life value (Feldman, 2004). In the author's case, he seemed to attribute positive intrinsic value to his ranch life experiences that, to certain extent, include solitude, and that is the logical reason why he indefatigably kept going back for more. Lastly, the Mental Statism notion accommodates the other two as this conception values a life based on the mental state of the person who lives that life (Feldman, 2004). The author was adamant that he wanted that kind of living to be his from day one as hinted in 'When we left I pressed my face to a dusty backseat window and cried' (Andrews, 2014, p. 6). This was depicted in his repetitious attempts to never let go of the sensation of living the hard life and willingness to trade work for pleasures like in '... I returned to the Zentz Ranch to work for nothing, or next to nothing, finding recompense in the little calluses on my palms' (Andrews, 2014, p. 6). This supports Thomas' (2017) assertion that solitude reflects a pleasure in solitary activities. This insinuates that the author was indiscernible with regard to intrinsic attitudinal pleasures, so his life was of equal intrinsic value for him. This paper has thus far discussed the author's preference for solitude from the hedonistic viewpoint of preranch life and will continue to do the same with other excerpts after he was hired as a ranch handler.

Into his first month of becoming the ranch hand, the author was tasked with fence fixing. After a few hours climbing the hill to mend fences, it took him a while to realise that he had reached the top and found himself staring out the vast expanse of land. At one point, he conceded defeat in 'At the midway point I was thoroughly browbeaten', and later, 'It was a shame: less than a month on the ranch and already the work was breaking me' (Andrews, 2014, p. 67). Despite sheer exhaustion, he took pleasure in his hard work, which he had completed all by himself. What he did here was carve out time for solitude. This identifies 
with Thomas (2017) as solitude seekers take a proactive approach to carve out solitary time. By this fact alone, this paper argues his worldview was hedonistic. The excerpt below proves that he was pleased about his state of affair as exhaustion and hard labour failed to diminish his pleasure.

\begin{abstract}
"I stood on the ridge's end. Beyond me the ground dropped precipitously away toward where the Madison River ran north for miles in its willow cradle. The winding course of it was frames on either side by mountains and was darker blue than the sky. For a moment, in spite of the sweat in my eyes or because of it, I saw the land more clearly than I ever had, and it was beautiful."
\end{abstract}

(Andrews, 2014, p. 67)

The use of environmental imagery informs his readership about the punitive natures of his ranching life, but towards the end of the excerpt, the idea of belonginess becomes abundantly perceptible as the author pointed out that the land below him "...it was beautiful (Andrews, 2014, p.67)". This is in keeping with the claim by Alvi, Vengadasamy, and Amrah (2019) that the use of environmental imagery helps invoke the sense of belonging. In fact, in the wilderness context, humans experience self-discovery, and gain transpersonal experiences (Heifetz, 2017). This is salient in the case of the author as he identified himself with the place. Everything was hedonistic as Universal AH points out that every pleasure-filled moment is every episode of intrinsic attitudinal pleasure (Feldman, 2004). The climb, the work completion, the beatdown, the exhaustion, etc., were the things that he was pleased about intrinsically. When Pure AH is considered, these forms of pleasure fundamentally contribute to the author's high valuation of his solitary living and as a proof, even amidst hardship, he took pleasure in the scenery whilst repressing the aspect of hard living into the back of his mind. Linked with this is what hedonism is all about - maximising pleasure, minimising pain (Feldman, 2004). Parallel to this concept is repression, a term Freud used when explaining 'unconscious'. It is a process and effect of keeping thoughts and experiences, especially unsettling ones, out of the conscious mind and into the unconscious (as cited in Barry, 2017). Then, Mental Statism postulates the author's mental states ascertain how he viewed life. This corresponds to the idea that the high valuation of his life stemmed from his pleasure-filled mental states.

The six features of intrinsic attitudinal pleasure further explain how his solitary life is of hedonism. Let us adopt these principles when examining the excerpt below:

\begin{abstract}
"As I looked down at the jaundiced wreckage of my palms, I felt a strange surge of pride. These weren't city boy hands. They weren't delicate by a long shot. From elbows down, the skin of my arms was covered with a chiaroscuro of barbwire scratches. The older ones had healed, peeled, and turned a dark, bluish color from the sun. More recent marks were zippered shut with lines of cracking scab. A few spots, either sliced today or bumped hard enough to reopen, were smeared with small patches of freshly dried blood."
\end{abstract}

(Andrews, 2014, pp. 90-91)

When we ponder the shocking state of his hands, one major component of hedonism emerges - Pain. There was no attempt made to minimise pain here, unlike what Hedonists unflinchingly suggest we do. Hedonists, however, would point out how he took pleasure in his permutations. His pain gave birth to pleasure, which then begot pride as he described the state of his hands - scratched, blemished, scarred, wounded and bleeding, and it seems like he had attained his desired image; a tough rancher rather than a delicate city boy. Schlau (2016) documented that the path of solitude to self-fulfilment is filled with "trials and contradictions" (p. 143). Despite the hardship, the author still maintained the state of solitude to claim the 
material space and spiritual space as suggested by Schlau (2016). His 'desired self' was projected in the tough ranchman image.

From the intrinsic attitudinal pleasure standpoint, the author was completely unaware of the fact that he took pleasure in completing his work. His pride surged despite the sufferings he received because, as this study argues in relation to solitude, he was able to finish his work unaided and unsupervised. This added credence to his solitary experiences undoubtedly. Then, there is this point about pleasure and belief. The author perceptibly took pleasure in his ability to complete a series of tasks assigned to him, again unaided and unsupervised, so he must believe it to be true, and assumedly the real pleasure was taken in once he was at the end of his workday. The next point, when seen with the excerpt, would imply that on the one hand, Andrews seemed to take pleasure, which led to his pride, in his rancher-like set of hands. On the other hand, he might be confused or mistaken about the object of his enjoyment. This study reiterates that hedonistically his object of pleasure was in fact his solo attempt to complete the list of tasks assigned to him.

The fourth feature asks this question concerning the author: Could he enjoy something that does not happen? Could he take pleasure in attitudinal pleasure that is not always directed towards truth? The excerpt below addresses the questions.

\section{"I got the feeling that I was clearing the country of elk, displacing the natives to make room for our vast, bawling herds of steers and heifers."}

(Andrews, 2014, p. 115)

Feldman (2004) suggests that we can take pleasure in a state of affairs that is unreal. The excerpt discloses the author seemingly took pleasure in replacing the native-species with human economic imperatives and the wild with the tame, which is assuredly not true at all. And the fact that he imagined he was doing it without help gave him the pleasure that he must at least think that it was true. This idea of pleasurable independent endeavour is ostensible as 'I' accomplished something for 'our', or us. Existentialist Soren Kierkegaard's (1813-1855) idea of 'subjective truth' (as cited in Burnham \& Papandreopoulos, n.d., para. 18) goes well with Feldman (2004) that pleasure can originate from the imaginative object of enjoyment. Kierkegaard would argue that all that matters is man's intensified emotions and willingness to believe in that which cannot be understood (as cited in Burnham \& Papandreopoulos, n.d., para. 18). In the author's case, his imagination was subjectively true as he was pleased about it. In addition, his idea of animal displacement, though imaginary, demonstrated his anthropocentric predisposition. Anthropocentricism posits "humans are unique, distinctive beings that ought to be assigned fundamental moral value in accordance with that distinctiveness" (Henriques, 2013, para. 2). The author's 'feeling' about species displacement was a moral-driven, human-centric instance fashioned into how he imagined he would treat the elk. Again, this correlates with the fourth feature that people can take pleasure in an imaginary state of affairs (Feldman, 2004). On to the fifth point, it says that an individual could be pleased about multitude of affairs simultaneously (Feldman, 2004). The excerpt below suggests the very notion of it.

"As I climbed up the Squaw Creek hogback, I briefly pictured the calf's gaping abdomen. Then I put it from my mind because the weather was so good, and I was determined to enjoy a rare moment of recreation."

(Andrews, 2014, p. 93)

In the excerpt, it clearly shows the author was pleased to be at Squaw Creek as the weather was good, pleased to be dreaming of his rare moment of recreation, and pleased to be thinking about having the place and all the time to himself - to be in solitude. And we can also 
mention something about the same excerpt in connection with the last principle: the temporal orientation of pleasure. The fact that the object of pleasure could be past-, present-, and futurerelated (Feldman, 2004), the excerpt has at least two. The good weather seemed to be pleasure in a present object as when the author was thinking about the mutilated calf, the weather at the time was good and the rare recreational moment seemed to show that pleasure was in a future object of enjoyment.

The next excerpt echoes the author's solitary quest of fulfilling his dream, which was to him, a rarity that occupied a special place in his heart as evidenced in the excerpt.

"We let the fire die when the storm broke, and rode together toward the higher pastures and the barn. Every tree was dripping and the creeks had swollen. It occurred to me that I had achieved a rare thing: I was living at the center of my heart's geography. And I knew it."

(Andrews, 2014, p. 103)

This paper would argue he was in a place he called home where his heart belonged. Self-fulfilment in solitude was apparent even if in people's presence. Frank (2015) points out that solitude as an experience is jointly shaped by the person and the people surrounding him. Hedonistically, Mental Statism would describe his life value relied on his mental state. Contentiously, everything he achieved, in his mind, was his own doing. And since he valued this highly (it was a rare thing), his life was of equal intrinsic value for him.

The author took pleasures in a solo 'expedition' completing a series of mundane tasks as shown in the excerpt.

"Every day in early July led me on some type of great or little expedition. Each morning I
set out with a long list of tasks that were scattered across the ranch: I might begin
setting out salt for the steers, roll east to check fence at the base of the mountains, swing
north to fix a broken gate, then finish up by cleaning leaves and detritus from the spring box
on Bad Luck Creek."

(Andrews, 2014, p. 114)

His work nature required the task completion went unaided and unsupervised. This placed him in solitude in which he discovered satisfaction as no remark was made regarding his 'expedition' being menial and repetitive. To label ranching as an expedition demonstrates he took pleasure in it by assigning it a particular purpose. Pure AH perceives such effort is an attribution of positive intrinsic value to the author's life.

One's impulse for pleasure usurps one's concern for safety as evidenced in the next excerpt.

"When Jeremy worried aloud that they (wolves) might return for a beef buffet, I started sleeping out with the cattle. It was a perfect job for me, really. James had his family. Jeremy had a girlfriend. Instead of going home alone, I kept company with the black outlines of mountains and innumerable stars."

(Andrews, 2014, p. 116)

In the case of the author, the willingness to take a risk with his own life and comfort in service for other people was for no other reason, but pleasure. This means he would be singlehandedly grappling with the strenuous nature of his work as well as be left all alone by himself as he prioritised pleasure that originated from solitude. More importantly, his image as a rancher would substantially improve as he would do everything by himself as indicated in the adjectival 'perfect' job. His willingness found its root in Universal AH. Intrinsically, everything he was willing to do here was out of sheer pleasure. UAH agrees with this as every episode of intrinsic attitudinal pleasure is in itself good. 
As portrayed by the extract, zipping into his sleeping bag symbolises protection from the outside world, an act of keeping his solitude intact.

"As I zipped into my bag, I could not help thinking that, though I was paid to watch and protect the cattle, I wanted little to do with them. The wolves were what I had come for - to see and hear them, and maybe even keep them from getting into trouble. They, and not the bawling yearlings, had brought me into the foothills at night."

(Andrews, 2014, p. 117)

Any impending danger (like wolves) did not deter him to be out there alone whilst getting his job done independently. Danger or any other form of distraction poses no threat to anything the author had faith in as he took pleasure in his effort and was pleased about the state he was in. IAH views his effort as the episodes of intrinsic attitudinal pleasure that ascertained his intrinsic life value.

This study argues that the author's preference for solitude stems from his hedonistic perspectives. As separate notions, solitude and hedonism have been extensively studied in literary discourse resulting in numerous interpretations across geographical, cultural and linguistic contexts. But library research unearthed a lacuna in the body of knowledge as little or no research exists to singularise these concepts as an interpretative means of intertextual analyses. Therefore, this study responds to this growing need of filling the gap. Findings disclose that the author's features of solitude are justifiable through this theory of hedonism. Pleasures are derived from the ranching aspects, and their sensations are heightened in solitariness. Feldman (2004) states pleasure is seen as an attitude in Attitudinal Hedonism, and this attitudinal pleasure is always object-directedness. Empirically every facet of ranching, according to the theory, is one episode of intrinsic attitudinal pleasure as well as one object of pleasure that increase the author's intrinsic life value. Ranching, in reality, entails independent task completions in unassisted and unsupervised working environments. Theory wise, if ranching is collectively viewed as one episode of pleasure that is good intrinsically, its intrinsic value must be equal to the amount of pleasure contained in it. This is in keeping with Thomas (2017) who asserts that connection with the inner self entails enjoyment of solitary activities. The corollary of this is if the author's life comprises ranching aspects that are intrinsically good, the theory suggests that the intrinsic value that he assigned to the life was tantamount to the pleasure it contained. Here, ranching is merely a means to impose solitude via (1) the nature of ranch work, (2) the nature of workplace (3) the disposition of the author, i.e. willingness and inclination, which hedonistically attest that the author was manipulative of the situation. In other words, pleasure in solitude by all means was advertently sought by taking advantage of ranching and its nature. Borrowing the author's testimony "... was a perfect job for me, really." (Andrews, 2014, p.116), the emphasis is placed upon the author's penchant for pleasure taking at work. The nature of his work coupled with his propensity for reclusiveness place him in the trajectory of, as the theory sees it, evaluating his life as intrinsically good episodes of intrinsic attitudinal pleasure.

\section{IMPLICATION}

The direction that this literary endeavour has taken is the intersection of solitude with hedonism. Findings have shown that solitude can be so strongly linked to hedonism. In the context of the book, solitude is seen as pleasure and the derivation of this pleasure-filled solitude is ranching and its nature, i.e. the nature of ranch work; the nature of workplace, and the author's predisposition for solitude. Hedonism is premised on the maximisation of pleasure and the minimisation of pain. The author has successfully maximised pleasure by leading a solitary lifestyle and by capitalising on the natures of ranching, i.e. works completed on 
individual basis and in remote locations, and these natures of ranching help protract the author's exposure to solitary experience. The Attitudinal Hedonism theory, founded on its three tenets; Universal Attitudinal Hedonism, Pure Attitudinal Hedonism; Mental Statism, fundamentally views pleasure as an attitude. Universal Attitudinal Hedonism sees the author's experienced pleasures are universally important and valuable as rationalised by the author himself. Pure Attitudinal Hedonism sees the author's solitary efforts as an attribution of positive intrinsic value to his own life. Mental Statism suggests the author's mental states determine the value of the lifestyle he led, which he regarded highly as positive. The author's experienced pleasures are ascertained to be intrinsically good through the application of Feldman's (2004) six features of intrinsic attitudinal pleasure. All in all, the theory of Attitudinal Hedonism has helped detail how solitude is so strongly linked to hedonism. The intersectionality is demonstrative of the author valuing his reclusiveness as pleasure, and the natures of ranching provide links to a prolonged solitary experience that he exclusively professed as pleasurable.

\section{CONCLUSION}

This paper studies interdisciplinarity of solitude, hedonism and literature in a nonfiction by Bryce Andrews. Using the theory of Intrinsic Attitudinal Hedonism and the six intrinsic attitudinal pleasure features, the study demonstrates the common linkage between voluntary retreat and hedonism in literary discourse. This is made possible through words and expressions extracted from some excerpts that highlight the motif of solitude. Subsequently, these excerpts were closely examined and interpreted within the theory domain. The analysis discloses that despite living in solitude, the author was pleased about the state he voluntarily placed himself in and took pleasure in stewardship of the ranch land. Therefore, being in solitude is arguably a form of pleasure taking inasmuch the completion of his work went on unaided and unsupervised. This hedonistic effort was palpably and effectively exerted when presented with hard choices and laborious working environment insofar as ranching was concerned. The author's cognitive state perceived episodes of intrinsic value of his ranching endeavour equal to the intrinsic value of his life. These episodes of taking pleasure in every completion of work without any help (working in solitude) were construed in themselves good; thus, the author's favourable treatment of the aspects of ranching was rationalised. By and large, pleasure found its way in all the things he did and was intensified by the fact that those things were lone endeavours. The self-attribution of intrinsic positive value to the life grants ranching an access to, to use the author's own terminology, 'the center of my heart's geography'. The findings of this study are advantageous in terms of interdisciplinary awareness augmentation and interdisciplinary studies facilitation when solitude, hedonism and literature are taken into account.

\section{REFERENCES}

Alvi, A., Vengadasamy, R. \& Amrah Abdul Majid. (2019). The philosophy of nature in the poetry of Ghulam Sarwar Yousuf and William Wordsworth: A comparative ecocritical analysis. GEMA Online ${ }^{\circledR}$ Journal of Language Studies. 19(4), 1904-17. http://doi.org/10.17576/gema-2019-1904-17

Andrews, B. (2014). Badluck Way: A Year on the Ragged Edge of the West. New York: Atria Paperback.

Barry, P. (2017). Beginning Theory: An Introduction to Literary and Cultural Theory ( $4^{\text {th }}$ ed.). Manchester: Manchester University Press.

Bentham, J. (1789). An Introduction to the Principles of Morals and Legislation. London: T. Payne and Son. 
Berlin, I. (1999). The Roots of Romanticism. Henry Hardy (Ed.). Princeton, New Jersey: Princeton University Press.

Bessetti-Reyes, G. M. (2014). Women and the American wilderness: Responses to landscape and myth (Doctoral dissertation). Available from Proquest Dissertations and Theses A\&I database. (UMI No. 3615032)

Bolea, S. (2017). Of hatred and solitude in the works of Mary Shelley and E. M. Cioran. Philobiblon. Transylvanian Journal of Multidisciplinary Research in Humanities. 22(2), 105-16.

Burnham, D. \& Papandreopoulos, G. (n.d.). Existentialism. Retrieved April 11, 2020 from https://www.iep.utm.edu/existent

Coplan, J.R. \& Bowker, J.C. (2014). All alone: Multiple perspectives on the study of solitude. In Coplan, J.R. \& Bowker, J.C. (ed.). The Handbook of Solitude: Psychological Perspectives on Social Isolation, Social Withdrawal, and Being Alone, pp. 3-13. West Sussex. John Wiley \& Sons.

Crowley, J. M. (2020). Montana. Retrieved August 8, 2020 from https://www.britannica.com/place/Montana-state

Crowell, S. (2017). Existentialism. Zalta, E. N. (ed.) Retrieved March 23, 2020 from https://plato.stanford.edu/archives/win2017/entries/existentialism.

Damiani, J. (2016). Same-sex desire, hedonism, and struggling identity in Johann Wolfing Von Goethe's Faust: A Tragedy (1806) and Oscar Wilde's the Picture of Dorian Gray (1981). https://doi.org/doi:10.7282/T34B33F0

Eagleton, T. (2020). A history of solitude by David Vincent; a biography of loneliness by Fay Bound Alberti-review. Retrieved March 19, 2020 from https://www.theguardian.com/books/2020/mar/19/history-solitude-david-vincentbiography-loneliness-fay-bound-alberti-review

Frank, P. (2015). The ends of aloneness: Scenes of solitude in nineteenth-century fiction (Doctoral dissertation). Available from Proquest Dissertations and Theses A\&I database. (UMI No. 3672849)

Feldman, F. (2002). The good life: A defense of attitudinal hedonism. Philosophy and Phenomenological Research. 3, 604-628.

Feldman, F. (2004). Pleasure and the Good Life: Concerning the Nature, Varieties, and Plausibility of Hedonism. Oxford: Clarendon Press.

Haines-Eitzen, K. (2018). What the joyous solitude of early hermits can teach us about being alone. Retrieved March 19, 2020 from https://theconversation.com/what-the-joyoussolitude-of-early-hermits-can-teach-us-about-being-alone-90804

Heifetz, A. (2017). Alone in the Wilderness: An Intuitive Inquiry into Lived-Experience of Prolonged Solitude in Wild Natural Settings. (Doctoral dissertation). Available from Proquest Dissertations and Theses A\&I database. (Proquest No. 10784410)

Henriques, G. (2013). On Human Exceptionalism. Retrieved April 11, 2020 from https://psychologytoday.com/us/blog/theory-knowledge/201301/humanexceptionalism.

Hijab, M. (2018). The problems with Liberalism. Retrieved March 28, 2020 from https://salam.org.uk/2018/10/01/the-problems-with-liberalism

Holton-Johnson, R. A. (2012). Restorative erotica: "Let the friend, and the lover be handsomely mixed" (Master's Thesis). Available from Proquest Dissertations and Theses A\&I Database. (UMI No. 1510512)

Jotischky, A. (2011). A Hermit's Cookbook: Monks, Food and Fasting in the Middle Ages. London: Continuum International Publishing Group. 
Khosravi, G. D., Vengadasamy, R. \& Raihanah, M. M. (2017). Ecoethical significance of wilderness in Pablo Neruda's selected poems. GEMA Online ${ }^{\circledR}$ Journal of Language Studies. 17(3), 1703-04. http://doi.org/10.17576/gema-2017-1703-04

Lambert, P. (2015). Where agriculture and aesthetics go hand-in-glove. Retrieved March 18, 2020 from https://www.hcn.org/issues/47.16/where-agriculture-and-aesthetics-gohand-in-glove

Lyon, T. J. (2001). This Incomparable Land: A Guide to American Nature Writing. Minnesota: Milkweed Editions. Macdonald, G. (2020). With self-isolation top of mind, David Vincent explains the differences between solitude and loneliness. Retrieved March 28, 2020 from

https://www.theglobeandmail.com/life/article-with-self-isolation-top-of-mind-davidvincent-explains-the/

Marshall, H. W. (n.d.). The Cowboy's Creed. Retrieved August 9, 2020 from https://www.loc.gov/collections/ranching-culture-in-northern-nevada-from-1945-to1982/articles-and-essays/buckaroo-views-of-a-western-way-of-life/the-cowboyscreed/

Marshall, H. W. (n.d.). Vaqueros. Retrieved August 9, 2020 from https://www.loc.gov/collections/ranching-culture-in-northern-nevada-from-1945-to1982/articles-and-essays/buckaroo-views-of-a-western-way-of-life/vaqueros/

Milner, E. 'Is there anybody there?': Solitude and the hermeneutics of love in the writings of Walter de la Mare. Journal of Language, Literature and Culture. 65(1), 50-59.

Moore, A. (2019). Hedonism. The Stanford Encyclopedia of Philosophy. Zalta, E.N. (ed). Retrieved March 28, 2020 from https://plato.stanford.edu/archives/win2019/entries/hedonism

Pritchett, L.R. (2004). Ranch literature: Writing the code of the new west (Doctoral dissertation). Available from Proquest Dissertations and Theses A\&I database. (UMI No. 3150820)

Ranching. (n.d.). National Geographic. Retrieved August 9, 2020 from http://nationalgeographic.org/encyclopedia/ranching/\#: :text=Ranching\%20in\%20the \%20western\%20United,the\%20so-called\%20open\%20range.

Ranching in Montana. (n.d.). The Montana Department of Natural Resources \& Conservation. Retrieved August 9, 2020 from http://dnrc.mt.gov/divisions/cardd/rangeland-resourceprogram/montana-grass-conservation-commission/ranching-in-montana

Scheese, D. (1996). Nature Writing: The Pastoral Impulse in America. New York: Twayne Publishers.

Schlau, S. (2016). A nest for the soul: The trope of solitude in three early modern discalced Carmelite nun-poets. International Journal of Medieval and Modern Literature and Culture. 7, 132-149.

Thomas, V. D. (2017). How to be alone: an investigation of solitude skills (Doctoral dissertation). Available from Proquest Dissertations and Theses A\&I database. (UMI No. 10287880)

Torralbo Caballero, J. D. D. (2015). Hedonism, pleasure and authenticity in restoration literature: Three textual inquiries in libertine poetry. Societal Studies. 6(1), 135-155.

Vincent, D. (2020). A History of Solitude. Cambridge: Polity Press.

Weijers, D. (n.d.). Hedonism. Retrieved March 9, 2020 from https://www.iep.utm.edu/hedonism 


\section{ABOUT THE AUTHORS}

Mohd Zaimin Haris Fathillah is a PhD student at Faculty of Social Sciences and Humanities, Universiti Kebangsaan Malaysia (The National University of Malaysia). His research interests include postcolonial literature and the teaching of literature.

Ravichandran Vengadasamy $(\mathrm{PhD})$ is a senior lecturer at the Faculty of Social Sciences and Humanities, Universiti Kebangsaan Malaysia. He is currently the Head of Programme for Masters by Coursework and the Coordinator of the English Literature Programme at the faculty. His research and teaching interests include Malaysian literature in English, postcolonial literature, stylistics and academic writing. 